\title{
Scrutiny of COVID-19 response strategies among severely affected European nations
}

\author{
Shine Stephen ${ }^{1}{ }^{\oplus}$, Alwin Issac $^{1}{ }^{\oplus}$, Rakesh Vadakkethil Radhakrishnan $^{1}{ }^{\oplus}$, Jaison Jacob $^{1}{ }^{\oplus}$, \\ VR Vijay $^{1 \oplus}$, Sam Jose $^{1 \oplus}$, SM Azhar $^{1 \oplus}$, Anoop S. Nair $^{1 \oplus}$, Nadiya Krishnan $^{1}{ }^{1}$, Rakesh Sharma $^{2}$, \\ Manju Dhandapani ${ }^{3}$ (i)
}

${ }^{1}$ College of Nursing, All India Institute of Medical Sciences, Bhubaneswar, India

${ }^{2}$ College of Nursing, All India Institute of Medical Sciences, Rishikesh, India

${ }^{3}$ National Institute of Nursing Education, Post Graduate Institute of Medical Education and Research (PGIMER), Chandigarh, India

Received: March 17, 2021

Revised: June 23, 2021

Accepted: June 29, 2021

Corresponding author: Shine Stephen Department of Nursing, College of Nursing, All India Institute of Medical Sciences, Bhubaneswar, 751019, India E-mail: shinestephentn@ gmail.com

\section{ABSTRACT}

Although the health care systems in Europe are considered the global benchmark, European nations were severely affected by the coronavirus disease 2019 (COVID-19) pandemic. This manuscript aimed to examine the strategies implemented to combat the COVID-19 pandemic by France, the United Kingdom, Spain, Italy, Germany, and Russia and their outcomes in terms of the number of cases, testing, and deaths. This is the first review of its kind that extensively analyzes the preparedness, mitigation, and response strategies against the COVID-19 pandemic adopted by these nations. This paper further suggests a strategic preparedness model for future pandemics. From the analysis, we found that a decentralized approach, prompt decision-making and timely execution, coordination between local health authorities, and public participation in the implementation of strategies could substantially reduce the case fatality rate. Nations with a high percentage of gross domestic product invested in the health sector, as well as more nurses, physicians, hospital beds, intensive care unit beds, and ventilators, better managed the pandemic. Instead, nations that postponed their pandemic response by delaying tracking, tracing, testing, quarantine, and lockdown were badly affected. The lessons learned from the present pandemic could be used as a guide to prepare for further pandemics.

Keywords: Coronavirus; COVID-19; Europe; Health policy; Pandemics

\section{Introduction}

On December 31, 2019, health authorities from Wuhan, China informed the World Health Organization (WHO) about an increase in pneumonia cases of unknown origin. On January 7 , 2020, Chinese health authorities detected the novel coronavirus as the causative agent of the pneumonia cases, and the virus was initially named "2019-nCoV," which was later renamed 
as severe acute respiratory syndrome coronavirus 2 (SARS-CoV-2) and the disease as coronavirus disease 2019 (COVID-19). Owing to the virulence and the contagious nature of the virus, the WHO declared the novel coronavirus outbreak a public health emergency of international concern on January 30, 2020 [1,2]. With the steep rise in infections outside China, the WHO declared the outbreak to be a pandemic on March 11, 2020 [3].

On January 24, 2020, France was the initial country in the European Union (EU) to report a coronavirus case [4]. Since then, there has been a steady rise in the number of cases in the EU countries. As of March 10, 2021, a total of $35,636,156$ cases had been reported from the EU, wherein 846,378 people succumbed to the illness [5]. The European lifestyle of taking a summer holiday abroad and "mass movement" of holidaymakers soon after the relaxation of draconian lockdown measures has been a significant factor in spreading the disease. While some countries were hit harder during Europe's first wave, the second wave was felt more widely and included countries that largely escaped the initial outbreak. Although vaccination against COVID-19 started in December 2020, COVID-19 maintains its foothold in EU countries.

Nations that prudently executed surveillance, quarantine, lockdown, and isolation were able to tame the virus, whereas those that delayed were severely affected by the pandemic [6]. The Global Health Security (GHS) index ranks countries based on their preparedness to counteract epidemics and related capabilities. It was believed that the nations that ranked top in the GHS index would manage the pandemic well, but the real scenario was different. This review aimed to examine the COVID-19 containment strategies employed by the worst-affected European countries and their impact on COVID-19 management, which could guide other nations in planning their strategies against upcoming pandemics.

\section{Materials and Methods}

A thorough literature search was performed to retrieve the containment strategies of the selected nations between January 2020 and February 2021, using Science Direct, Scopus, MEDLINE, Google Scholar, and the official websites of the WHO and the concerned nations. The keywords were COVID-19, pandemic, SARS-CoV-2, preparedness, and containment strategies. Among the European nations, the most affected countries (Russia, Germany, Spain, France, Italy, and the United Kingdom [UK]) were selected. The available data from these countries included COVID-19 cases (date of the positive index case, number of tests performed, number of positive cases, and deaths), mitigation (availability of human resources, personnel protective equipment arranged, number of hospital beds including critical care beds with facilities for mechanical ventilation and other strategies) and response (screening and isolation facilities, implementation of lockdown, public relations, and restricted travel). Since mortality is a precise appraisal of the progression and outcome of a pandemic [7], with which the management strategy of a nation can be evaluated, the death rate (per million population) was fixed as the primary endpoint for evaluating the outcome of measures taken by these 6 selected nations.

\section{Preparedness and Containment Strategies}

The victory of a nation over a pandemic strongly depends upon the existing health care system (in terms of health infrastructure, early mobilization of available resources, services rendered by trained health care professionals), expertise in dealing with an emergency, and the early mitigation strategies adopted. The response of each nation to the pandemic in terms of identifying the severity, reducing the incidence of infections and the mortality rate, supporting health care professionals, and safeguarding vulnerable populations exhibits the preparedness of the nation for managing the pandemic. Adequate preparedness not only reduces the strain on the health care system, but helps to cope promptly with the health consequences of the pandemic.

\section{France}

France reported the index COVID-19 case on January 24, 2020, which was also the primary case reported in the EU as a whole [8]. Unchecked communal gatherings, transmission of infection through sailors and airline carriers, and local municipal elections paved an easy way for the infection to spread among the French population [8,9]. On January 27, 2020, a health crisis center was established and the Pasteur Institute developed a rapid diagnostic kit. With the aim of preparing the health care system to face a pandemic of global concern, on February 13, 2020, the organization plan for the response of the health system (ORSAN) was activated [10]. On March 5, 2020, gatherings of more than 5,000 people in enclosed spaces were banned, and the number of people permitted to gather was further reduced in the following days. A ban of ships carrying more than 100 people calling in or anchoring in inland and territorial waters came into force on March 14 [11]. A lockdown was imposed on March 17, 2020 and later extended until May 11, 2020 (Figure 1A) [12]. Commonly employed preventive strategies, such as physical distancing, personal hygiene, limitation on public gatherings, use of face masks in public spaces, periodic ventilation of closed spaces, and isolating 
cases with symptoms and testing them as early as possible, were enforced by the health authorities [13]. With the successful implementation of these containment measures, the number of cases per day was limited to 120 on May 17, 2020.

By the end of July 2020, people's complacency regarding hygiene measures during the summer and lifting of restrictions led to the emergence of the second wave, and France reported its highest number of COVID-19 cases on November 7, 2020 (86,852 cases) since the beginning of the pandemic [14]. At the end of June 2020, the incidence rate, effective reproduction number $(\mathrm{R})$, and reverse transcription-polymerase chain reaction (PCR) positivity rate were 5.14 (per 100,000 population), 0.99, and $1.44 \%$ respectively, but by the end of November 2020, these values increased to 491 (per 100000 population), 1.4, and $20 \%$, respectively [15]. With the surge in coronavirus cases, further restrictions were imposed on public movement and social gatherings, such as night curfews, lockdowns, and border closure to nations outside the EU. As of March 10, 2021, France still has weekend lockdown measures in place in active circulation zones. Witnessing a resurgence of coronavirus cases, hospitals were geared up with more intensive care unit (ICU) beds to accommodate new cases [16]. On March 10, 2021, France had a total of around 3.9 million coronavirus cases, or approximately 60,624 cases per million population (Figure 1B) [5].

\section{Germany}

Germany was not among the EU countries initially hit by
COVID-19. Germany reported its index case on January 27,2020 . Taking heed from other severely hit countries, Germany's risk-averse attitude and proactive behavior presumably enabled limited draconic measures in the country compared to other EU countries. By mid-March, stringent measures to contain the pandemic were enforced, including a "contact ban" that delimited public assemblage to 2 people (outside families), physical distancing measures of at least 1.5 meters, and shutdown of schools and nonessential businesses [17]. However, a curfew was never imposed. Travelers arriving in the country from high-risk nations had to quarantine for a fortnight and were urged to furnish information about potential exposure along with their contact information. Borders to adjoining countries were closed on March 15, and a lockdown was imposed until April 19, 2020 [17].

The German government made it mandatory for all health care providers to notify any suspected cases of COVID-19 to local public health authorities within 24 hours. Germany's national pandemic plans were in accordance with the guidelines of the Robert Koch Institute (RKI), and they mandated the publication of periodic situation reports for national and international public health zones. Having a response plan in place and being a federalized country allowed the government to counteract the pandemic quickly. Protocols for testing, case detection, contact tracing, and treatment strategies were prepared even before the index case was reported [18]. Having laboratories with proficiency, accreditation, and machinery to conduct PCR assays and announce diagnoses, Germany scaled up their testing capacity.

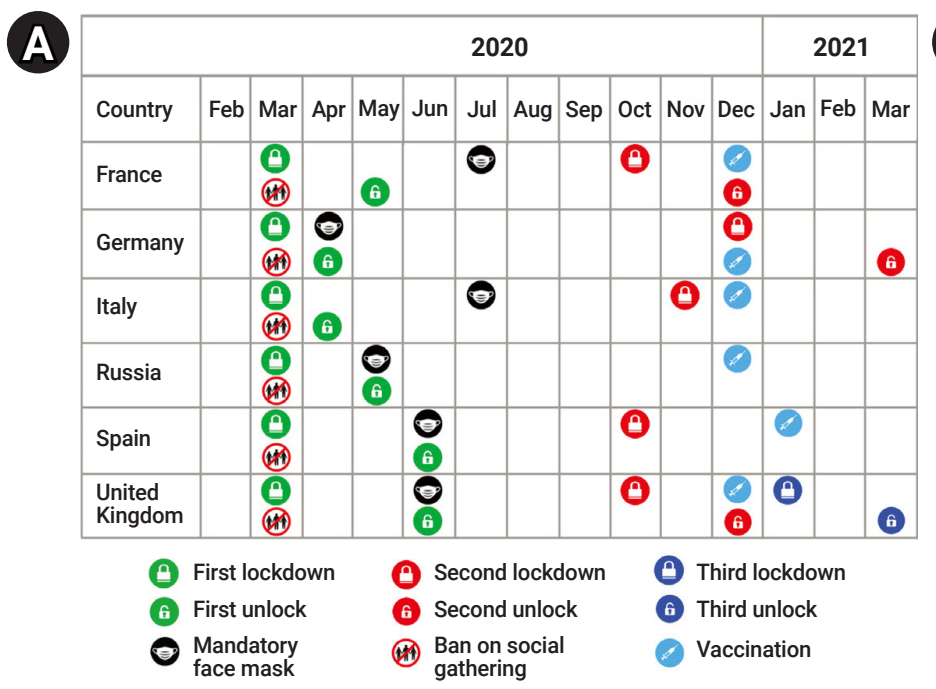

B

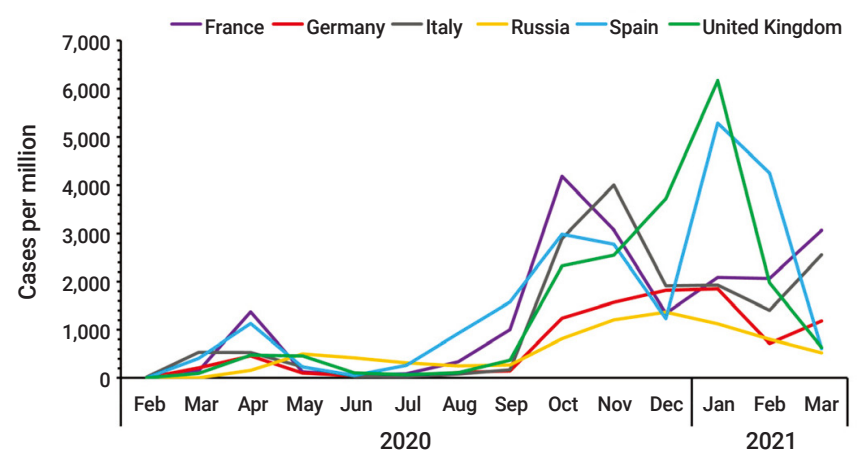

Figure 1. (A) Timeline comparing containment measures against coronavirus disease 2019 (COVID-19). (B) Timeline comparing coronavirus cases per million population among the selected nations. 
Testing was made free of cost to everyone upon medical or epidemiological indication through the Coronavirus Relief Bill. As of March 10, 2021, Germany reported 30,164 cases per million population and 873 deaths per million populations, which signifies the quality of Germany's health care system (Table 1).

\section{United Kingdom}

The UK refers to a political union between England, Wales, Northern Ireland, and Scotland. The UK reported its index case of COVID-19 on January 31, 2020, even though screening for travelers from Wuhan, China started by late January at Heathrow airport [19]. Upon early reports of the outbreak from Wuhan, Public Health England, the main agency responsible for health advice and directives, raised the risk level of the pandemic from "very low" to "low" and subsequently to "moderate" following declaration of the outbreak as a public health emergency of international concern [20]. The governmental response against the pandemic was based on the national pandemic influenza plan of 2011, which delivers data about the expected impact of the pandemic and provides certain norms to aid in planning the pandemic response [21]. Later, written guidelines were made available at all airports for unwell travelers, and people returning from affected countries were advised to self-isolate for a fortnight if they developed flu-like symptoms [21]. Authorities urged the public to refrain from non-essential travel and to avoid social gatherings. On February 10, the government enacted the Health Protection (Coronavirus) Regulations-2020 act, which provided discretionary powers to the authorities to impose quarantine under threat of legal proceedings and to impose restrictions on people and situations leading to spread of the virus. The government-imposed closure of public places (pubs, restaurants, indoor sports and other leisure facilities) under the provisions of these regulations, and hospitals started drive-through testing centers for COVID-19 [22].

Although the UK initiated testing for detecting coronavirus cases in January 2020, it conducted very few tests until the middle of March. As of March 31, 2020, the country's testing rate were only up to 5,000 tests in a day; a much lower figure than in other European countries [23]. A lockdown was not imposed until March, 2020; later, a "stay at home" order was announced to save lives and protect the National Health Service (NHS) staff. The government passed the Coronavirus Act-2020 on March 19, which granted the government power to regulate areas of health service, social care, and public activities including local councils [24].

Until March 3, 2020 a definitive action plan was not drafted by the government despite witnessing early spread of virus throughout February. A public health information campaign with the slogan "Catch it, bin it, kill it" was launched to limit the spread of the virus within the country by facilitating behavior change among the public [25]. The 2020 UK local elections were postponed for a year on March 13 as a precautionary measure. On April 2, the government announced a "fivepillar" strategy to scale up virus testing in the UK, which included intensifying swab testing in public labs and NHS hospitals, nationwide surveillance, and capacity-building, to have 100,000 tests a day. Although the UK enforced containment measures against the spread of COVID-19, the months preceding September observed some relaxations in imposed restrictions, including the reopening of higher schools, which led to a resurgence of infections during September. Owing to all these factors, the government was forced to impose a second lockdown (Figure 1A). On December 14, 2020 , the health authorities of the UK reported a new SARSCoV-2 variant, "SARS-CoV-2 VUI 202012/01" (variant under investigation, year 2020, month 12 , variant 01 ), to the WHO; this variant is much more transmissible than the previous strain [26]. As of March 10, 2021, the UK reported 4,234,924 cases and 124,987 deaths from COVID-19. Notably, the UK has the highest deaths per million among the nations investigated herein (Table 1).

\section{Spain}

The first case of COVID-19 was confirmed in Spain on January

Table 1. COVID-19: incidence, CFR, and recovery Index of selected nations

\begin{tabular}{clccc}
\hline GHS rank & Country & $\begin{array}{c}\text { Deaths per } \\
\text { million population }\end{array}$ & CFR (\%) & Recovery index \\
\hline 2 & United Kingdom & 1,834 & 2.9 & 66.79 \\
11 & France & 1,370 & 2.3 & 60.30 \\
14 & Germany & 873 & 2.8 & 72.62 \\
15 & Spain & 1,539 & 2.1 & 54.38 \\
31 & Italy & 1,669 & 3.4 & 58.66 \\
63 & Russia & 622 & 2.0 & 70.38 \\
\hline
\end{tabular}

Data as on March 10, 2021 (source: http://www.worldometers.info).

COVID-19, coronavirus disease 2019; CFR, case fatality rate; GHS, Global Health Security. 
31, 2020, after a German traveler tested positive in La Gomera, Canary Island. Shortly thereafter, all direct flights from affected nations to Spain were canceled from March 10 to March 25, 2020, and a lockdown was imposed on March 14, 2020, which was later extended through June 21 (Figure 1A). Borders were closed, and all non-essential employees were asked to stay at home from March 30 to April 9, 2020 to flatten the curve and contain the pandemic [27]. A COVID-19 diagnostic application, CoronaMadrid, was developed by the Spanish government; this self-assessment application encouraged COVID-suspected nationals to perform an assessment when they thought they had COVID-19 symptoms. People received instructions and recommendations about COVID-19, through the same application [28]. On October 20, 2020, Spain became the first European nation to report 1 million cases. With the resurgence of coronavirus cases after an initial decline, stringent measures were employed, including a partial lockdown (October 21, 2020), declaration of emergency (October 25, 2020), imposition of overnight curfew, and reinforced quarantine. Spain still dominates the $\mathrm{EU}$ in the number of coronavirus cases per million population $(67,963)$ (Table 1) [29]. The scarcity of ICU beds, ventilators, and numerous health care workers falling ill led to a high death rate (1,539 deaths per million population) [29]. Among the 6 European countries analyzed, Spain still has the lowest recovery index (54.38) (Table 1).

\section{Russia}

The world's largest country by area, Russia reported its index COVID-19 case on January 31, 2020 [30]. Russia prepared for the ongoing pandemic through repurposing existing facilities, building new hospitals, procuring the requisite diagnostic and resuscitation equipment, and embarking upon intense and swift retraining of their health care workers. When the outbreak began, the health administration created more than $1,77,000$ beds exclusively for COVID-19 patients, including 25,000 ICU beds [31]. In collaboration with the Russian health authorities, the Ministry of Defense created 800 multifunctional bedded medical centers in several regions of Russia to treat COVID-19 patients. Around 2,000 highly skilled doctors, nurses, and other medical staff were deployed at various medical centers. The national government allocated 8.8 billion Russian rubles (approximately 120 million United States dollars) to set up these infectious disease centers [32].

In an unprecedented measure, Russia suspended all national and international regular flights except rescue flights bringing Russian citizens by March 27, 2020 [33]. Trains to China and North Korea were also suspended and work visas to Chinese citizens stopped being issued on February 19, 2020. On March 30, in a bid to curb the spread of COVID-19, Russia closed its borders completely except for goods and cargo [34]. In October 2020, owing to the surge in coronavirus cases, a night-time curfew was implemented and the use of face masks was made mandatory. A nationwide aggressive testing regimen was put in place, which was later appreciated by the WHO. On December 15, 2020, the nation started a vaccination program against COVID-19 to halt the rise in cases (Table 2). On March 10, 2021, Russia had conducted more than 113 million COVID-19 tests (779,571 tests/million population) [29]. Russia has 29,873 cases per million population (Table 1) [29]. Among the severely affected European countries, Russia has the lowest death rate, with 622 deaths per million population and a case fatality rate (CFR) of $2 \%$, which is the lowest among the nations studied (Table 1) [35].

\section{Italy}

COVID-19 entered Italy on January 31, 2020, through 2 Chinese tourists. With the identification of the primary coronavirus cases, a state of emergency was declared and all flights to and from China were suspended. Since the first confirmed case, emergency medical number-112 was designated exclusively for COVID-19, and the emergency medical team performed a primary assessment, screening, counseling, or hospitalization based on the situation at hand.

Table 2. COVID-19 vaccination status in the selected nations

\begin{tabular}{|c|c|c|c|c|}
\hline Country & $\begin{array}{l}\text { Start date } \\
\text { (mm/dd/yyyy) }\end{array}$ & Vaccine manufacturer & $\begin{array}{l}\text { Population } \\
\text { vaccinated } \\
\text { (million) }\end{array}$ & $\begin{array}{l}\text { Doses administered } \\
\text { per } 100 \text { people }\end{array}$ \\
\hline United Kingdom & $12 / 12 / 2020$ & $\begin{array}{l}\text { Pfizer/BioNTech, AstraZeneca, } \\
\text { Moderna }\end{array}$ & 23.77 & 35.02 \\
\hline France & $12 / 27 / 2020$ & Pfizer/BioNTech & 5.97 & 8.80 \\
\hline Germany & $12 / 27 / 2020$ & Pfizer/BioNTech & 8.16 & 9.74 \\
\hline Spain & $01 / 04 / 2021$ & AstraZeneca & 4.85 & 10.37 \\
\hline Russia & $12 / 15 / 2020$ & Sputnik V & 6.69 & 4.59 \\
\hline
\end{tabular}

Data as on March 10, 2021 (source: ourworldindata.org).

COVID-19, coronavirus disease 2019. 
Initially, Italy did not screen contacts linked to confirmed cases or recent travelers to outbreak regions until they showed symptoms. By February, partial quarantine was imposed on identified clusters, and on March 9, 2020, a quarantine was imposed all over the country. A nationwide lockdown came into force from March 10 until April 13, 2020 (Figure $1 \mathrm{~A}$ ). As a primary initiative, all the residents of Vò (a commune in Italy) were screened, including those who did not have symptoms, which allowed them to quarantine and reduce the spread of the virus. Technological advances, specifically artificial intelligence-powered robots, were deployed in hospitals to screen and care for patients.

With a loosening of containment strategies, Italy witnessed a second wave of the pandemic by July 2020. Shortly thereafter, a state of emergency was declared, use of face masks was made mandatory in public gatherings, and demonstrations and meetings were banned. The health system was restructured and expanded with the installment of sophisticated ICU beds. Millions of doses of flu vaccine were procured to be distributed among the public [36]. All schools and universities remained closed from October 15, 2020 until October 30, 2020. By the end of October, a regional lockdown was imposed in affected areas. Although vaccination was started on December 27, 2020 , it was not sufficient to control the increasing number of coronavirus cases, as the initial doses of vaccines were administered to health care workers and immuno-compromised people. On March 10, 2021, Italy had 51,711 cases per million population and a high CFR of 3.4\% (Table 1) [29]. It is predicted that the situation will further deteriorate with the invasion of newer virus strains (e.g., the UK, Brazilian, and South African variants) and scarcities in vaccine supply [37].

\section{Discussion}

The actual response of each country to COVID-19 did not correlate well with their respective GHS index (Table 1). It was predicted that the nations occupying the top positions in the GHS index would perform better during a pandemic. However, in the real scenario, the nations with well-established primary health care that employed advanced health technology with transparent communication demonstrated a remarkable performance. This was also evident in their respective global COVID-19 recovery index (GCI). The daily recovery status of patients from COVID-19 is taken into consideration to evaluate the GCI [38]. Germany and Russia stood high among the nations studied in terms of the GCI (Table 1). The measures followed by these nations could serve as a guide for other nations in the present and upcoming pandemics.

Until the end of July 2020, France maintained the number of coronavirus cases under control, whereas there was an upsurge in the number of cases starting in August 2020 [39]. Digital technology was aptly employed, wherein precise data regarding the pandemic were procured and communicated with the public, and contact tracing was reinforced with the help of technology. Amidst the upsurge of coronavirus cases, numerous religious meetings and municipal elections were held, leading to a further escalation of cases [9]. Even though there was a change in the political structure after elections in July 2020, the health care policies pertaining to social care remained unchanged. France experienced one of the world's worst outbreaks of COVID-19 in the spring, and cases increased after the first phase of the lockdown (March 16, 2020 to May 11, 2020). Despite the exquisite French public health system, the operation of top-down, centralized control measures slowed their response to the fast-moving crisis. Owing to their shortage in the logistic capacity in terms of scanty accredited laboratories and reagents for testing; widespread testing could not be practiced, resulting in 1370 deaths per million population (Table 1) [5]. The number of physicians per 1,000 population was also very low (3.3 per 1,000 population) when compared to France's counterparts (Figure 2). In a recent study published, only 31\% of persons with having COVID-19-like symptoms sought medical care despite governmental recommendations [40]. France hopes to contain the spread of pandemic through its vaccination program [41].

The index case of coronavirus in Germany was reported from Munich, which is home to a biosafety level-3 lab that had the capacity to perform PCR testing shortly after China released the genetic sequence of the coronavirus. By the time initial clusters of cases were brought under control, protocols were established and in place for diagnosing, isolating, and treating COVID-19 patients safely. Germany was quick to lockdown (Figure 1A) and scaled up its testing capacity, and then repeatedly adapted this program to respond to changes in the epidemic dynamics. Widespread testing is acknowledged as the primary reason for a lower number of deaths per million population (873 deaths) in Germany, as it enabled the detection and management of cases at an earlier stage. The decentralized approach to managing a pandemic was a good way to deal with a quickly changing pandemic. This was accomplished by collaborating with local health authorities through the RKI, which tailored responses according to local needs. Being the fourth-largest economy in the world, Germany spends roughly $11 \%$ of its gross domestic product (GDP) on health care (Figure 2) [42]. In the EU, Germany has the highest number of hospital beds (8.3), nurses (13.2) and physicians (4.2) per 1,000 people (Figure 2) $[43,44]$. When COVID-19 arrived in Germany, ICU bed capacity was increased from 12,000 to 40,000 


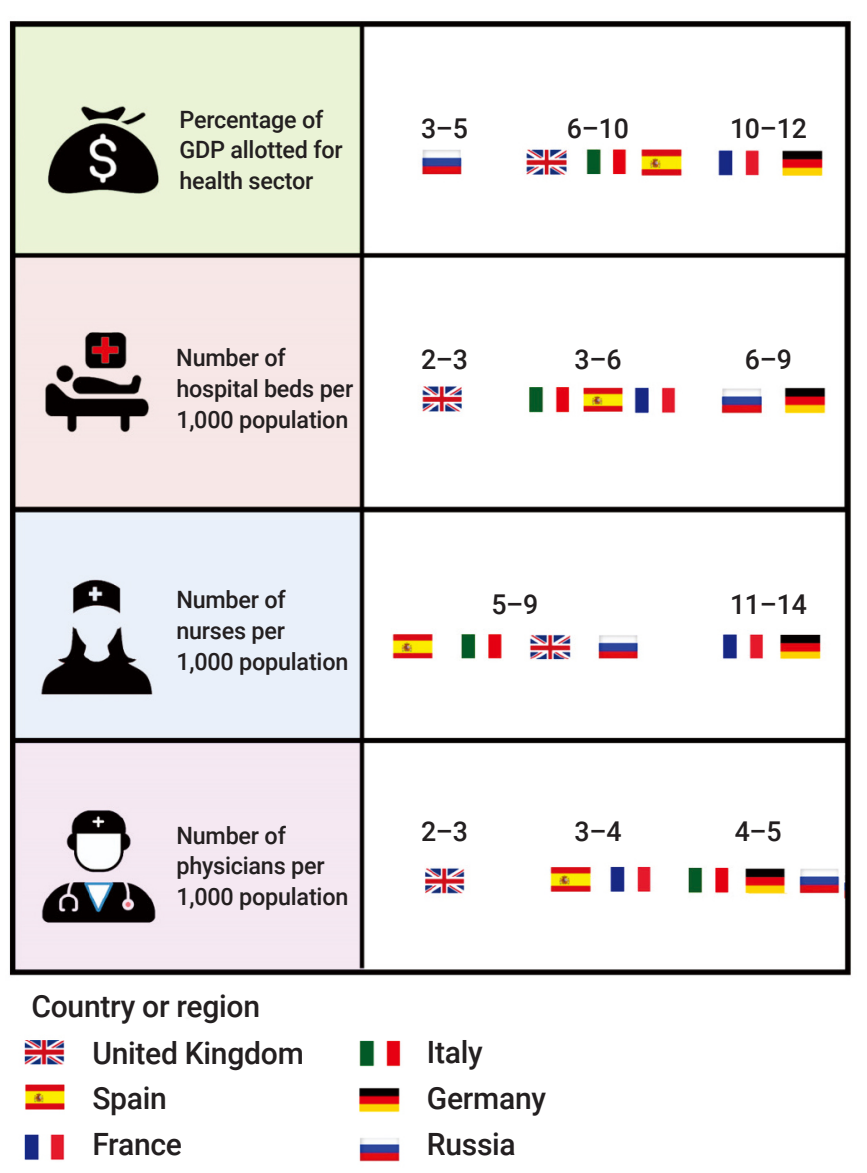

Figure 2. Existing health system capacities of the selected nations. GDP, gross domestic product.

beds quickly. This is considered the primary reason why Germany achieved a brilliant recovery index (72.62) (Table 1), which was the highest among the nations studied. Citizens and permanent residents of Germany are covered through health insurance. Endowed with ample human resources and physical infrastructure, Germany possesses a robust health care system, which-in combination with the rapid initial advances that were made after the detection of COVID-19-augmented Germany's efficacious containment strategies. The restrictions imposed by the government were wholeheartedly accepted by the public and became vital in curtailing the progression of the pandemic. The federal system of the government focused on collecting and analyzing the data and transparently communicating outcomes to the people, leading to unusual levels of public support. Judicious decision-making at the highest level of the government, relying on expert advice from scientists mixed with the trust that the public holds in the government, enabled Germany to manage the crisis swiftly.

The GHS index ranks countries based on their preparedness for epidemics and related capabilities. Although the UK occupies the second position in GHS ranking among all 195 nations, the UK's health system was overstretched well before the pandemic hit the UK (Table 1). Among the UK's 19 counterpart nations, the UK had the third-lowest number of available hospital beds per 1,000 population [45]. The nation believed in and propagated herd immunity as a permanent solution to contain the pandemic, despite the WHO's warning regarding tracking, tracing, and isolating COVID-19 cases. In response to widespread criticism regarding the government's delayed approach to initiate mass testing and tracing of infected COVID-19 cases, attempts were made to increase the testing capacity [46]. With the nation's precarious delay in combating the pandemic, the CFR rose to $11.56 \%$, which was much higher than the global average and the average among the UK's European counterparts. The health care capacity in terms of beds was also very low (2.5 per 1,000 population) when compared to the other selected nations (Figure 2). Although a contact tracing app was developed through the NHS in the first week of May 2020, alleging security reasons, its implementation was suboptimal [47]. However, since September 2021, with the resurgence of the second wave of the virus and the emergence of the mutated variant (UK strain), the government was forced to tighten containment measures, including lockdowns, after a phased easing of imposed restrictions. On December 2, 2020, with the arrival of the Pfizer/BioNTech vaccine against COVID-19, the UK was the first country to approve a vaccine for use in humans. By December 8, an immunization program was launched [48]. As of February 26, 2021, 3 vaccines have been approved to be used in the UK, which has announced the goal of vaccinating all UK nationals by the end of July 2021 (Table 2).

The COVID-19 pandemic tested the integrity, strength and pandemic preparedness of the Spanish health care system. A health alert and emergency coordination center was established in 2004, with the aim of identifying and controlling situations causing health crises (national and/or international) that significantly affect the public health [49]. The response towards the COVID-19 pandemic signifies the importance of scrutiny of the Spanish health care system, which was believed to be a strong health sector. The increase in the number of cases was attributed to the letdown of both societal and governmental norms. Basic infection control measures, like social distancing and use of face masks, were erroneously not followed during the initial phases of the pandemic [50]. The latest survey results from the WHO and Spain's Carlos III Institute of Health revealed that almost half of the Spanish citizens still believed that there was only a low to medium risk of contracting the virus 
through social gatherings [51].

The economic crisis of 2008 debilitated Spain's public health and health system capacity. The health care system was shrunken, leading to a severe reduction in the number of health care providers. The health care system operated with an extremely low level of personnel (5.9 nurses per 1,000 population), whereas the EU is reported to have 9.3 nurses per 1,000 population (Figure 2) [52]. A decentralized health care system under 17 autonomous communities [53] and the presence of a significant proportion of the elderly population resulted in a mortality rate of 1,539 per million population (Table 1). Moreover, studies have suggested that Spain might have underestimated the infection and mortality rates due to the negligence in reporting and lack of a robust testing strategy [54]. The use of low-quality testing kits is also considered a reason for the upsurge in the number of cases.

Since Russia shares China's land boundaries, Russia had the potential to become a major focus of epidemic spread. With the advent of COVID-19 in China, numerous systematic steps were implemented by the Russian Federation, including administrative, organizational, technical, sanitary, and hygienic measures. These initiatives have given Russia to prepare to handle the situation, divert human and fiscal resources, and boost the health care system's readiness to deal with the epidemic. Russia is the only nation in which the public health service is kept accountable for its citizens' sanitary and epidemiological welfare. The system is well equipped with approximately 100,000 trained professionals, including epidemiologists, researchers, scientists, and technicians. The sanitaryepidemiological service succeeded in preventing the primary transmission of COVID-19 from mainland China, which further provided adequate time to prepare and reorganize the health care facilities to combat the pandemic. Airports, railway stations, and other public transport facilities were well equipped with sanitary quarantine centers (SQC), in which epidemiologists worked relentlessly to check the occurrence of any infectious disease in the Russian Federation. SQCs played a pivotal role in the prevention of the spread of COVID-19 in Russia [55].

The Russian health care system's response towards COVID-19 was deeply ingrained through its historical inheritance of the Semashko health system (named after Dr. Nikolai Semashko, one of the major founders and organizers of the public health system in the Soviet Union), which already emerged victorious by successfully delivering universal health coverage to the Russian citizens by 1930 . The Semashko tradition has made the therapeutic health care system inclined towards institutional-based medical services. Consequently, Russia's physician-to-population ratio (4 per 1,000 population) and available hospital beds (7.1 per 1,000 population) have been quite high in comparison to its European counterparts for decades (Figure 2) [56]. This has helped the Russian health care system launch a better institutional response during the pandemic. Other judicious responses like timely border closure, the long experience of the public health care system in controlling infectious diseases like plague, enhanced testing capacity, economic stimulus measures, low population density across the country, and digitalization in public health may have effectively limited the fatality rate compared to other nations. The overall governmental measures against COVID-19 met the requirements of quality, availability, and provision of health care services, drugs, and other consumables. The endurable investment in health care and the prudent implementation of measures combating COVID-19 helped Russia take the upper hand over the pandemic by limiting the CFR to $2 \%$ (Table 1) with a recovery index of 70.38 (Table 1).

Although Italy was placed in the 31st position in the GHS index ranking, the Italian health system occupies the second position in overall health system performance among 191 countries. The Italian constitution ensures the right to health and free medical to all its citizens, based on the principles of universality, equality and equity through Article 32. Health care in Italy is delivered through 3 different levels of health services: primarily through collective preventive and public health (including preventive measures through vaccinations and health promotion campaigns); secondly through district assistance with health and social health activities and services (e.g., outpatient services, home care, rehabilitation, and old age homes); and thirdly through hospital services [57]. With expenditures of $8.8 \%$ of the GDP on health, Italy has not been able to provide adequate health care to the public due to the increasing number of elderly people (Figure 2). Moreover, the Italian health care system relies on a triage policy, wherein critically ill patients receive health care rapidly, whereas less critically ill patients have to wait for their turn. Unfortunately, the majority of the COVID-19 patients are either asymptomatic or have mild to moderate symptoms. During the early stage of the pandemic, the Italian health care system failed to identify these patients, which resulted in a surge of COVID-19 cases. This strategy stressed the already exhausted health care system and caused the situation to deteriorate. Furthermore, the highly decentralized health care delivery system, lack of proper testing strategy, shortages in the supply of personal protective equipment for health care providers, lack of preparation to face a pandemic, and lack of proper protocols for the initial management of COVID-19 patients made the situation arduous [58,59]. 


\section{What Steps Can Nations Follow?}

Owing to increased encroachment into wildlife habitats, the COVID-19 pandemic will not be the last time a virus would threaten human existence [60]. The unprecedented COVID-19 pandemic has challenged existing health care systems and revealed their efficiency (or lack thereof). The nations that were able to contain the virus have reiterated the perennial truth that multi-level coordinated and comprehensive strategies are imperative to combat any outbreak from progressing into a pandemic. It is imperative to note that a reasonable proportion of GDP investment in health, including the health system capacity in terms of the number of physicians, nurses, and hospital beds served as a feature demarcating nations' pandemic responses (Figure 2). Hence, nations could adopt sensible efforts for capacity-building and resource allocation for the health sector.

The strategies ought to pay due attention to all phases of the preparedness and response framework (prevention, preparedness, response, and recovery) (Figure 3). In the academic curriculum, emphasis should be placed on the significance of having a balanced human ecosystem and the repercussions that could result from encroachment into wildlife. Biosafety labs should be relentlessly monitored and reinforced to prevent any accidental or intentional entry of viruses into the outside world. As a dilemma exists regarding the origin of SARS-CoV-2, the recent G7 summit reiterated the need for a better understanding of the origin of the virus [61]. The public must be educated and should incorporate health behavior practices into day-to-day life. All of these steps could prevent pandemics.

During the preparedness phase, epidemiological institutes should be built, which could help with the swift identification of a virus and its characteristics. It is imperative for every nation to have tailored pandemic preparedness plans, and the plans should be tried out during inter-pandemic periods to evaluate their efficiency and flaws. As primary health centers (PHCs) remain the initial contact between patients and the health care system, PHCs should be

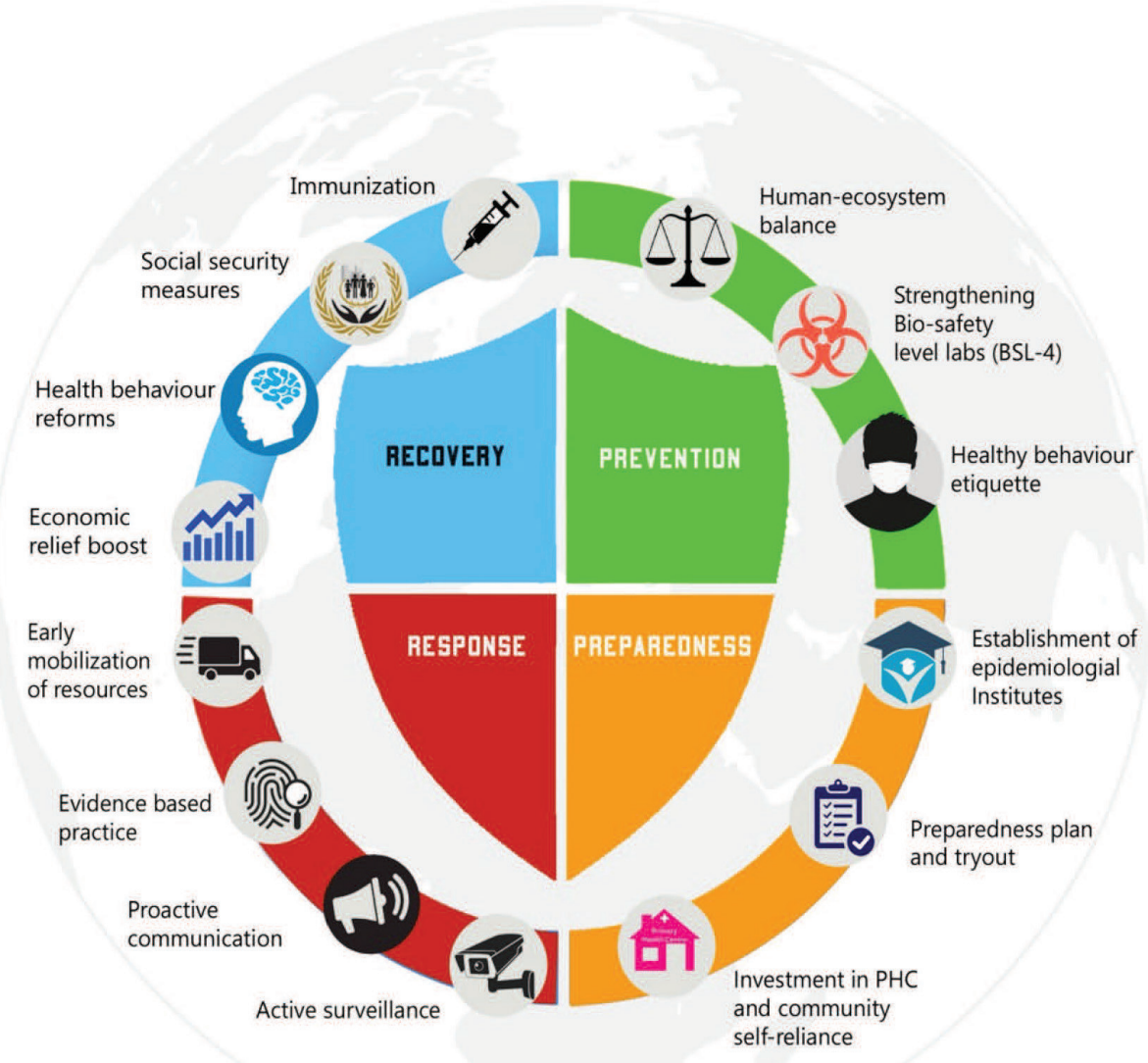

Figure 3. Global strategic model for future pandemics. $\mathrm{PHC}$, primary health center. 
fostered. Boosting industrialization could help nations to be independent in fulfilling their needs $[62,63]$. Dependence on other nations for commodities resulted in exportation and importation of the virus on a global scale.

In the response phase of a pandemic, communicating "what is unknown" along with "what is known" to the general public would ensure their cooperation and trust towards the government. A nation needs to act in accordance to its pandemic preparedness plan or in accordance to evidencebased practices $[64,65]$. Resources should be mobilized in accordance to priorities and needs. Active surveillance should be carried out to identify all cases. Adequate investment in technology would help with all these response strategies.

Immunization and health behavior reforms, such as hand washing, mask wearing, and social distancing, could curtail transmission. An economic relief package would ameliorate the downswing in business and trade. These measures are key in the recovery phase of the pandemic.

\section{Limitations}

Written health care policies of the described nations were not explored in detail. Most of the data retrieved were from online sources and the ground reality may vary. However, this was a meaningful appraisal of the COVID-19 pandemic preparedness and response strategies of the most strongly affected European countries.

\section{Conclusion}

Although the strategies in combating the pandemic were identical among European countries, the timing and rigor of their execution led to differences in the number of coronavirus cases and CFR. Nations with a centralized, governmentrun health care system and a decentralized local health care execution fared better in response to the surge in coronavirus cases. The responses were directed and backed by timely political will. Furthermore, in many nations, early adoption of stringent containment strategies reduced the transmission speed. None of the EU countries were completely prepared to deal with the COVID-19 pandemic, as had been widely predicted. Nations with a robust health care infrastructure, sufficient health care human resources, and a high percentage of GDP invested in the health sector will effectively combat future pandemics.

\section{Notes}

\section{Ethics Approval}

Not applicable.

\section{Conflicts of Interest}

The authors have no conflicts of interest to declare.

\section{Funding}

None.

\section{Availability of Data}

All data generated or analyzed during this study are included in this published article. For other data, these may be requested through the corresponding author.

\section{Authors' contributions}

Conceptualization: AI, SS; Data curation: JJ, NK, RS, MD; Writing-original draft: SS, AI, RVR, SJ, SMA, ASN; Writing-review \& editing: NK, RS, MD.

\section{References}

1. Jelly P, Chadha L, Kaur N, et al. Impact of COVID-19 pandemic on the psychological status of pregnant women. Cureus 2021;13:e12875.

2. Jacob J, Vr V, Issac A, Stephen S, et al. Factors associated with psychological outcomes among frontline healthcare providers of India during COVID-19 pandemic. Asian J Psychiatr 2021;55:102531.

3. World Health Organization (WHO). Coronavirus disease (COVID-19) pandemic [Internet]. Geneva: WHO; 2020 [cited 2021 Feb 24]. Available from: https://www.euro.who.int/en/health-topics/health-emergencies /coronavirus-covid-19/novel-coronavirus-2019-ncov.

4. Bernard Stoecklin S, Rolland P, Silue Y, et al. First cases of coronavirus disease 2019 (COVID-19) in France: surveillance, investigations and control measures, January 2020. Euro Surveill 2020;25:2000094.

5. Worldometers. Coronavirus update (live): 118,714,747 cases and 2,633,819 deaths from COVID-19 virus pandemic [Internet]. Worldometers [cited 2021 Mar 11]. Available from: https://www.worldometers.info/ coronavirus/.

6. Issac A, Stephen S, Jacob J, et al. The pandemic league of COVID-19: Korea versus the United States, with lessons for the entire world. J Prev Med Public Health 2020;53:228-32.

7. Zylke JW, Bauchner H. Mortality and morbidity: the measure of a pandemic. JAMA 2020;324:458-9.

8. Jacob E. Coronavirus: trois premiers cas confirmés en France, deux d'entre eux vont bien [Internet]. Le Figaro.fr; 2020 Jan 24 [cited 2020 Sep 11]. Available from: https://www.lefigaro.fr/sciences/coronavirustrois-premiers-cas-confirmes-en-france-20200124.

9. Le Point.fr. Coronavirus: la «bombe atomique» du rassemblement évangélique de Mulhouse [Internet]. Le Point.fr; 2020 Mar 28 [cited 2021 Feb 26]. Available from: https://www.lepoint.fr/sante/coronavirusla-bombe-atomique-du-rassemblement-evangelique-de-mulhouse -28-03-2020-2369173_40.php.

10. Gouvernement.fr. Les actions du Gouvernement [Internet]. Gouvernement. fr [cited 2020 Nov 11]. Available from: https://www.gouvernement.fr/ info-coronavirus/les-actions-du-gouvernement.

11. République Française. Légifrance [Internet]. République Française [cited 2020 Sep 15]. Available from: https://journal-officiel.legifrance. gouv.fr/. 
12. BBC. Coronavirus: France eases lockdown after eight weeks [Internet]. BBC; 2020 May 11 [cited 2020 Sep 10]. Available from: https://www.bbc. com/news/world-europe-52615733.

13. Santé Publique France. Coronavirus : chiffres clés et évolution de la COVID-19 en France et dans le Monde [Internet]. Santé Publique France; 2020 [cited 2020 Nov 7]. Available from: https://www.santepubliquefrance. fr/dossiers/coronavirus-covid-19/coronavirus-chiffres-cles-et-evolution -de-la-covid-19-en-france-et-dans-le-monde.

14. Worldometers. France coronavirus: 387,252 cases and 30,950 deaths [Internet]. Worldometers [cited 2020 Sep 15]. Available from: https:// www.worldometers.info/coronavirus/country/france/.

15. Etalab. Etalab-covid19-dashboard [Internet]. Etalab [cited 2020 Nov 11]. Available from: https://dashboard.covid19.data.gouv.fr.

16. Gouvernement.fr. Restrictions and requirements in metropolitan France [Internet]. Gouvernement.fr [cited 2020 Nov 6]. Available from: https://www.gouvernement.fr/en/coronavirus-covid-19.

17. Our World in Data. Policy responses to the coronavirus pandemic [Internet]. Our World in Data [cited 2020 Sep 16]. Available from: https://ourworldindata.org/policy-responses-covid.

18. Robert Koch-Institut. Influenza pandemic planning [Internet]. Robert Koch-Institut; 2019 [cited 2020 Sep 14]. Available from: https://www.rki. de/DE/Content/InfAZ/I/Influenza/Pandemieplanung/Pandemieplanung Node.html.

19. Ball T, Wace C, Smyth C, Brown D. Hunt for contacts of coronavirusstricken pair in York [Internet]. The Times; 2020 Jan 31 [cited 2021 Jan 5]. Available from: https://www.thetimes.co.uk/article/hunt-for-contactsof-coronavirus-stricken-pair-in-york-dh363qf8k.

20. Stephen S, Issac A, Jacob J, et al. COVID-19: weighing the endeavors of nations, with time to event analysis. Osong Public Health Res Perspect 2020;11:149-57.

21. GOV.UK. Coronavirus (COVID-19) in the UK: daily updated statistics [Internet]. GOV.UK [cited 2021 Jan 5]. Available from: https://www. gov.uk/guidance/coronavirus-covid-19-information-for-the-public.

22. Legislation.gov.uk. The health protection (coronavirus) regulations 2020 [Internet]. Legislation.gov.uk [cited 2021 Jan 5]. Available from: https://www.legislation.gov.uk/uksi/2020/129/contents/made.

23. Smith O. Coronavirus testing crisis: Ex-WHO chief exposes UK failure as 44 testing labs sit unused [Internet]. Express.co.uk; 2020 Mar 31 [cited 2021 Jan 5]. Available from: https://www.express.co.uk/news/ uk/1262707/Coronavirus-UK-testing-news-WHO-lockdown-labsBoris-Johnson-PHE-NHS.

24. Heffer G. Coronavirus bill: emergency laws to contain spread of COVID-19 published [Internet]. Sky News; 2020 Mar 20 [cited 2021 Jan 5]. Available from: https://news.sky.com/story/coronavirusbill-emergency-laws-to-contain-spread-of-covid-19-published11959342.

25. Russell P. New coronavirus: UK public health campaign launched [Internet]. Medscape; 2020 Feb 3 [cited 2021Jan 5]. Available from: https:// www.medscape.com/viewarticle/924664.

26. 2020 World Health Organization (WHO). SARS-CoV-2 variant - United
Kingdom of Great Britain and Northern Ireland [Internet]. Geneva: WHO; 2020 [cited 2021 Feb 26]. Available from: https://www.who.int/ emergencies/disease-outbreak-news/item/2020-DON304.

27. Legido-Quigley H, Mateos-García JT, Campos VR, et al. The resilience of the Spanish health system against the COVID-19 pandemic. Lancet Public Health 2020;5:e251-2.

28. oriXone. CoronaMadrid, the COVID-19 diagnostic app for the Community of Madrid, can now be downloaded on iPhone [Internet]. iGamesNews; 2020 Mar 25 [cited 2020 Apr 10]. Available from: https://www.igamesnews. com/mobile/coronamadrid-the-covid-19-diagnostic-app-for-thecommunity-of-madrid-can-now-be-downloaded-on-iphone/.

29. Worldometers. Coronavirus update (live): 112,714,134 cases and 2,498,093 deaths from COVID-19 virus pandemic [Internet]. Worldometers [cited $2021 \mathrm{Feb}$ 24]. Available from: https://www.worldometers.info/ coronavirus/?utm_campaign= homeAdUOA?Si.

30. TASS. First two persons infected with coronavirus identified in Russia [Internet]. TASS; 2020 Jan 31 [cited 2020 Nov 24]. Available from: https://tass.com/society/1115101.

31. TASS. Russia has over 177,000 beds for COVID-19 patients - deputy premier [Internet]. TASS; 2020 May 30 [cited 2020 Sep 22]. Available from: https://tass.com/world/1162077.

32. TASS. Russian military hospitals ready to admit civilians with COVID-19 [Internet]. TASS; 2020 May 20 [cited 2020 Sep 22]. Available from: https://tass.com/society/1158513.

33. Reuters. Russia to ground international flights on March 27 due to coronavirus [Internet]. Reuters; 2020 Mar 26 [cited 2020 Sep 22]. Available from: https://www.reuters.com/article/health-coronavirusrussia-flights/russia-to-ground-international-flights-on-march27-due-to-coronavirus-idUSL8N2BJONK? edition-redirect $=$ in.

34. Al Jazeera. Coronavirus: travel restrictions, border shutdowns by country [Internet]. Al Jazeera; 2020 Jun 3 [cited 2020 Sep 22]. Available from: https://www.aljazeera.com/news/2020/6/3/coronavirus-travelrestrictions-border-shutdowns-by-country.

35. Worldometers. Russia coronavirus: 2,114,502 cases and 36,540 deaths [Internet]. Worldometers [cited 2020 Nov 24]. Available from: https:// www.worldometers.info/coronavirus/country/russia/.

36. Jacob J, Stephen S, Issac A, et al. Determinants of willingness for COVID-19 vaccine: implications for enhancing the proportion of vaccination among Indians. Cureus 2021;13:e15271.

37. Bontempi E. The europe second wave of COVID-19 infection and the Italy "strange" situation. Environ Res 2021;193:110476.

38. Issac A, Radhakrishnan RV, Vijay VR, et al. An examination of Thailand's health care system and strategies during the management of the COVID-19 pandemic. J Glob Health 2021;11:03002.

39. Worldometers. France coronavirus: $3,427,386$ cases and 81,448 deaths [Internet]. Worldometers [cited 2021 Feb 13]. Available from: https:// www.worldometers.info/coronavirus/country/france/.

40. Pullano G, Di Domenico L, Sabbatini CE, et al. Underdetection of cases of COVID-19 in France threatens epidemic control. Nature 2021;590:1349. 
41. Gouvernement.fr. Vaccins [Internet]. Gouvernement.fr; 2021 [cited 2021 Feb 13]. Available from: https://www.gouvernement.fr/info-coronavirus/ vaccins.

42. Tikkanen R, Osborn R, Mossialos E, et al. International health care system profiles: Germany [Internet]. The Commonwealth Fund; 2020 [cited 2020 Sep 14]. Available from: https://www.commonwealthfund. org/international-health-policy-center/countries/germany.

43. The World Bank Group. Hospital beds (per 1,000 people) - Germany [Internet]. The World Bank Group [cited 2020 Sep 14]. Available from: https://data.worldbank.org/indicator/SH.MED.BEDS.ZS?locations = DESmost_recent_value_desc $=$ true.

44. The World Bank Group. Physicians (per 1,000 people) - Germany [Internet]. The World Bank Group [cited 2020 Sep 14]. Available from: https:/data. worldbank.org/indicator/SH.MED.PHYS.ZS?locations = DE\&most_ recent_value_desc $=$ true.

45. Hunter DJ. Covid-19 and the stiff upper lip-the pandemic response in the United Kingdom. N Engl J Med 2020;382:e31.

46. Booth W. U.K. resists coronavirus lockdowns, goes its own way on response? [Internet]. The Washington Post; 2020 Mar 16 [cited 2021 Jan 5]. Available from: https://www.washingtonpost.com/world /europe/uk-coronavirus-herd-immunity/2020/03/16/1c9d640e66c7-11ea-b199-3a9799c54512_story.html.

47. Dearden L. Coronavirus: NHS contact-tracing app must not be released to public without privacy protections, MPs say [Internet]. The Independent; 2020 May 7 [cited 2021 Jan 5]. Available from: https://www.independent.co.uk/news/uk/home-news/coronavirus -nhs-contact-tracing-app-covid-19-uk-release-date-privacyprotection-a9503321.html.

48. Statista. Europe: COVID-19 vaccination rate by country 2021 [Internet]. Statista [cited 2021 Mar 1]. Available from: https://www.statista.com/ statistics/1196071/covid-19-vaccination-rate-in-europe-by-country/.

49. The Lancet Public Health. COVID-19 in Spain: a predictable storm? Lancet Public Health 2020;5:e568.

50. Tremlett G. How did Spain get its coronavirus response so wrong? [Internet]. 2020 Mar 26 [cited 2020 Apr 10]. Available from: https:// www.theguardian.com/world/2020/mar/26/spain-coronavirusresponse-analysis.

51. COSMO-SPAIN. Monitorización del comportamiento y las actitudes de la población relacionadas con la COVID-19 en España (COSMOSPAIN): Estudio OM [Internet]. COSMO-SPAIN [cited 2020 Oct 30]. Available from: https://portalcne.isciii.es/cosmo-spain/.

52. Organisation for Economic Co-operation and Development (OECD). Nurses [Internet]. OECD [cited 2020 Oct 30]. Available from: http:// data.oecd.org/healthres/nurses.htm.
53. HealthManagement.org. Overview of the Spanish healthcare system ? [Internet]. HealthManagement.org [cited 2020 Nov 1]. Available from: https://healthmanagement.org/c/hospital/issuearticle/overview -of-the-spanish-healthcare-system.

54. Lau H, Khosrawipour T, Kocbach P, et al. Evaluating the massive underreporting and undertesting of COVID-19 cases in multiple global epicenters. Pulmonology 2021;27:110-5.

55. Reshetnikov V, Mitrokhin O, Shepetovskaya N, et al. Organizational measures aiming to combat COVID-19 in the Russian Federation: the first experience. Expert Rev Pharmacoecon Outcomes Res 2020;20: 571-6.

56. Jakovljevic MB, Nakazono S, Ogura S. Contemporary generic market in Japan - key conditions to successful evolution. Expert Rev Pharmacoecon Outcomes Res 2014;14:181-94.

57. France G, Taroni F, Donatini A. The Italian health-care system. Health Econ 2005;14(Suppl 1):S187-202.

58. Armocida B, Formenti B, Ussai S, et al. The Italian health system and the COVID-19 challenge. Lancet Public Health 2020;5:e253.

59. Indolfi C, Spaccarotella C. The outbreak of COVID-19 in Italy: fighting the pandemic. JACC Case Rep 2020;2:1414-8.

60. Walsh MG, Sawleshwarkar S, Hossain S, et al. Whence the next pandemic ? The intersecting global geography of the animal-human interface, poor health systems and air transit centrality reveals conduits for high-impact spillover. One Health 2020;11:100177.

61. Ministry of External Affairs, Government of India. G7 and Guest Countries: 2021 Open Societies Statement [Internet]. Ministry of External Affairs, Government of India; 2021 Jun 13 [cited 2021 Jun 23]. Available from: https://mea.gov.in/bilateral-documents.htm?dtl/33910 /G7+and+Guest+Countries+2021+Open+Societies+Statement.

62. Swain D, Vijay VR, Das H, et al. Combit response to COVID-19 pandemic in Odisha: future public health challenges and measures. Int J Community Med Public Health 2021;8:979-85.

63. Issac A, Vijay VR, Krishnan N, et al. How the nations should gear up for future pandemics? J Glob Health 2021;11:03075.

64. Jacob J, Vijay VR, Issac A, et al. Somatoform symptoms among frontline health-care providers during the COVID-19 pandemic. Indian J Psychol Med 2021;43:272-4.

65. Vijay VR, Krishnan N, Issac A, et al. Safeguarding the frontier Covidians during the COVID-19 pandemic: scuffles and proposed strategies. Indian J Psychol Med 2021;43:89-90. 